\title{
Implementing R\&D policies: an analysis of Spain's pharmaceutical research program
}

\author{
Klaus Desmet ${ }^{\mathrm{a}, \mathrm{b}, *}$, Praveen Kujal ${ }^{\mathrm{a}}$, Félix Lobo ${ }^{\mathrm{a}}$ \\ a Department of Economics, Universidad Carlos III de Madrid, Getafe (Madrid)28903, Spain \\ ${ }^{\mathrm{b}} C E P R, U K$
}

\begin{abstract}
We analyze Spain's National Pharmaceutical Research Program using detailed firm-l vel data. We fin differences between ex ante announced evaluation criteria and ex post implementation. This suggests that judging R\&D programs on their design, rather than their implementation, may be misleading. We also uncover that the apparent discrimination against non-European firm can be interpreted as a premium to having local production facilities. Overall, the program values firm on the basis of criteria, such as R\&D investment and patent spending, consistent with empirically tested measures of innovative activity.
\end{abstract}

Keywords: Innovation policy; Pharmaceutical industry; R\&D programs

\section{Introduction}

Given its importance, the design of public support programs for innovation has received much attention (Martin and Scott, 2000; Trajtenberg, 2002). To evaluate the effectiveness of such programs, the literature has relied on both case studies and firm-l vel microeconometric evidence (Klette et al., 2000; Hall and Van Reenen, 2000). However, between a program's design

* Corresponding author. Tel.: +3491624 9845; fax: +34916249875.

E-mail address: klaus.desmet@uc3m.es (K. Desmet). and its outcome there is an important intermediate step: its implementation. A well-designed program may fail if poorly implemented.

To judge the success of a program, one should take into account possible differences between its ex ante design and its ex post implementation. For instance, a program's design may claim it rewards firm on the basis of both research and commercial success. However, only its implementation can tell us how and whether the design was put into practice. Focusing on Spain's National Pharmaceutical Research Program, we use a unique firm-1 vel data set to explore these issues. Our aim is threefold: first we highlight the gap between de- 
sign and implementation; second, we analyze whether the implementation is broadly in line with the program's objectives of R\&D promotion; and, third, we try to uncover any other criteria that might have been used, such as possible discrimination in favor of Spanish firms

We look at Profarma, a Spanish government support program for pharmaceutical research that ran from 1998 to 2000. All firm applying to take part in Profarma were ranked by a committee of the Ministry of Science and Technology. This ranking translated into financia support and other non-monetary benefits such as faster approval or beneficia pricing of new drugs. The officia call for applications explicitly stated the ranking criteria. Using the application forms as our primary data source, we were able to extract manually all relevant quantifiabl criteria on a fir by fir basis. This information then allowed us to determine which of the criteria were effectively used, and their relative importance.

Our firs result is that there are indeed significan differences between the ex ante announced criteria and the ex post applied criteria. A number of variables specifi cally stated in the call for applications, such as having an $R \& D$ center or collaborating with other firm or institutions, turn out to be statistically unimportant under a variety of different specifications It is difficul to identify the reasons behind this divergence. Such differences may be due to discrepancies between the government's true objectives and it's announced policy, or they may reflec a gap between the policy define by the higher levels of government and its implementation by lower executive levels.

Our second result is that, in spite of the differences between the ex ante and ex post criteria, the program's implementation is broadly consistent with its objectives. The criteria, which end up determining the ranking of firms such as R\&D investment and patent spending, are in line with results from the empirical literature on innovative activity. As argued by Griliches et al. (1991), innovative success in the pharmaceutical industry is best measured by R\&D investment and patent counts. In that sense, Profarma did what it was set out to do: reward firm on the basis of their capacity to innovate.

Our third result is the uncovering of a hidden premium for Spanish and European Union firms More specificall, on a scale from 1 to 6 , the probability of getting a grade of 4 or above increases by 0.61 for Spanish companies, and by 0.45 for European Union firms However, after dropping the firm without production plants in Spain from the sample, this preferential treatment disappears. This suggests that producing locally is strongly rewarded. This can be interpreted in two ways. On the one hand, Profarma may be an indirect way of subsidizing production and employment, rather than $R \& D$. On the other hand, if the productivity of R\&D depends on local manufacturing, as argued by Pisano (1997), then rewarding local production amounts to stimulating R\&D.

The rest of the paper is organized as follows. Section 2 places our contribution in the wider literature on public R\&D programs. Section 3 gives some background on the Spanish government support plan to the pharmaceutical industry. Section 4 analyzes the Profarma program. Section 5 gives the conclusion.

\section{Related literature}

Public support programs for R\&D can be divided into three stages: design, implementation, and fina results. The literature has mainly focused on the design and the results, without paying much attention to the implementation. However, uncovering the differences between design and implementation is important, because the assessment and the eventual success of a research program has more to do with its implementation than with its design.

This is not to say that the existing literature has failed to take into account the implementation stage when evaluating the results of a research program. It is well known that public support is not allocated in a random fashion, so that controlling for how a program is implemented is standard practice in the empirical literature (Klette et al., 2000). To give an example, assume that R\&D subsidies are biased towards large firms and that fir size is positively correlated with private $R \& D$ spending. In that case, if one fails to control for fir size, the estimated effect of R\&D subsidies on private R\&D spending will be upward biased. The literature deals with this non-random selection in two ways. A firs approach is to control for a number of observable differences across firms such as sales or employment. This does not suffic if unobservable variables enter into the selection process. In that case, a second ap- 
proach consists in controlling for fir and time fi ed effects (see, e.g., Lach, 2002). Nevertheless, dealing with selection bias remains an arduous task, making it difficul to evaluate the effectiveness of public research programs. As a solution, some experts have suggested incorporating the need for evaluation in the design process of these programs (Jaffe, 2002).

Although the literature on evaluating public $R \& D$ programs takes into account how firm get selected, it typically falls short in explicitly uncovering how the implementation process works. ${ }^{1}$ As a result, it is unable to highlight the differences between design and implementation. The inability of addressing this issue derives from two problems. One, in most cases there is no good theoretical model of how a public support program is implemented. The lack of a structural model of government agency behavior makes evaluating public programs difficul (David et al., 2000). Two, even if there were a good theoretical model, there might not be a way of testing it for want of data. Controlling for certain observable fir characteristics might provide a partial answer. However, as soon as unobservables enter into play, there is no way of contrasting design and implementation.

We believe we have answers to both problems. The officia call for applications, in which the evaluation criteria are described in detail, is taken as our exogenously given theoretical model of the program's design. Regarding data, we consider the primary source, i.e., the application forms. It is therefore reasonable to assume that we have access to the same data as the Ministry of Science and Technology. By regressing the ranking of firm on the officia evaluation criteria we can test which criteria played a role and which did not. Of course one could argue that other criteria, not stated in the officia call, were also used to rank firms However, assuming that we have the same information as the Ministry, these other unofficia criteria would show up in the application forms. In principle, we should therefore be able to control for them. This is what we do, for instance, when we take into account the geographical origin of firms

Using the application forms as the primary data source is similar to the approach of Arora et al. (1998), who analyze the effects of public funding on research

\footnotetext{
1 Arora et al. (1998) is an exception to this. We will discuss their work in more detail later in the paper.
}

output in the Italian biotechnology sector. As in our paper, they are able to directly take into account the program's implementation. However, their focus is different from ours: rather than highlighting the difference between design and implementation, they are interested in measuring the productivity of public support.

Understanding the implementation process is key when evaluating public R\&D programs. The existing literature on this subject typically starts by describing the program's design, and then tests whether public support to $R \& D$ encourages private investment in $R \& D$ (Klette et al., 2000; David et al., 2000; Trajtenberg, 2002; Lach, 2002). These papers give the impression that they are evaluating the program's design. However, what they are in fact testing is the program's implementation. It is unclear how to interpret their results if design and implementation differ and if information on implementation is lacking. For instance, if one find that $R \& D$ subsidies substitute private $R \& D$ investment, this could be either because the program was badly designed or because it was badly implemented. The literature is of course aware of this problem, and it does mention, in passing, that results may be hard to interpret in the absence of an adequate model of implementation. For instance, Lach (2002) suggests that the effect of R\&D subsidies may be upward biased, because government bureaucrats tend to be under pressure to select projects that are sure to succeed. However, there is no way of backing up this suspicion. Some authors go some way in uncovering implementation biases. For example, Lerner (1999) shows that there is evidence that the government supports firm in backward regions in the case of the Small Business Research Innovation (SBIR) program. Overall, the literature has found no good way of explicitly studying how public R\&D programs are implemented. This is the contribution of our paper. Not only are we able to contrast the design and its implementation, we also show that concerns about differences between the ex ante announced criteria and the ex post applied criteria are real.

\section{Spain's National Pharmaceutical Research Program}

\subsection{Brief background}

Compared to most developed economies, Spain has been a laggard in total factor productivity growth. In 
the 1990's, TFP in Spain grew at an annual rate of $0.1 \%$, compared to $0.5 \%$ in the Eurozone, and $1.7 \%$ in the United States (Sebastián, 2001). It is by now widely believed that the lack of R\&D is one of the key problems of the Spanish economy. Only 1\% of GDP is spent on research and development, putting Spain 24th out of the 30 member countries of the OECD (2004). The number of researchers as a fraction of the labor force, although growing, is still significantl lower than in most developed nations. This absence of innovation is especially true in the private sector (Buesa and Molero, 1998; Martin, 1999; OECD, 2004; Myro, 2004).

Starting with the so-called "Science Law" of 1986, the Spanish government has attempted to correct this problem. $^{2}$ The public promotion of R\&D has been in the hands of the Center for Industrial Technology Development, which finance particular projects, and the Ministry of Science and Technology, which develops different sectoral initiatives. It turns out that one of the earliest initiatives was the R\&D support program for the pharmaceutical industry. This is hardly surprising, as it is one of the most technologically innovative sectors (Scherer, 2000).

An additional concern in the European context is the eroding competitive position of its pharmaceutical industry. A couple of decades ago innovation depended mainly on organic chemistry, Europe's traditional power base. In recent years, however, the pharmaceutical industry has been increasingly shifting towards biotechnology. This knowledge shift has also meant a geographical shift. With the possible exception of British firms the competitive edge of European companies has been disappearing, with the U.S. pharmaceutical industry becoming the clear leader (see Gambardella et al., 2000; Jacobzone, 2000). This has prompted European national governments and the European Union to design plans to counter this trend. ${ }^{3}$

The pharmaceutical industry in Spain has been a latecomer in R\&D. At the end of the seventies it was made up of multinationals and a large number of small family-owned laboratories. These small companies, which accounted for a substantial share of the mar-

\footnotetext{
${ }^{2}$ Ley 13/86 de promoción y coordinación general de la investigación científic y tecnológica.

3 See European Commission 93/718 (2 May 1994) for more details on the policy implications of the eroding competitive position of the European pharmaceutical industry.
}

ket, focused on the production of pharmaceutical specialities. They either imported active substances from countries with no patents, or they had license agreements with multinationals. The lack of patent protection opened the door for dynamic Spanish companies to copy new drugs, sometimes leading to developments in formulation and dosage.

The 1980s witnessed major restructuring, as multinationals took over many of the smaller Spanish firms which were unable to survive the breakup of the locally protected market. Spain's entry into the European Union exposed the national industry to greater competition. The common market meant the removal of both tariff and non-tariff barriers through, for instance, the harmonization of market regulations. In addition, the 1985 Adhesion Treaty obliged Spain to implement full patent protection, until then largely absent. This motivated the firs major initiative to support R\&D and innovation in the pharmaceutical industry.

When the National Pharmaceutical Research Program took off in 1986, the local industry lacked the capacity to innovate, R\&D was virtually non-existent, and Spain was absent from international markets. Government support to R\&D in the pharmaceutical industry has since then gone through four successive plans: Farma I (1986-1990), Farma II (1991-1993), Farma III (1994-1997) and Profarma (1998-2000).

\subsection{The Profarma plan: $1998-2000$}

This paper focuses on Profarma, the most recent public program supporting $R \& D$ in the pharmaceutical industry. It ran from 1998 to 2000, with the aim of "establishing a procedure to support research and the introduction of new production technologies for pharmaceuticals and raw materials". In the officia call for applications this objective was translated into four quantifiabl goals: first $R \& D$ expenses as a proportion of sales of ethical drugs should reach $8 \%$; second, R\&D expenses and investments should rise to 312 million $€$; third, there should be at least 3000 employees in research activities; and fourth, that the worsening trade balance should be improved.

Participating firm were evaluated and ordered into different categories. This ranking had different ramifi cations. On the one hand, it translated into financia aid for specifi research projects. This financia aid came in the form of direct subsidies or zero interest loans. 
On the other hand, receiving a good ranking enhanced a firm s reputation, which was useful for purposes of price setting and speedy approval of new products. Arguably, firm were mostly interested in this nonmonetary aspect, as the magnitude of subsidies was limited: it represented a mere $2.20 \%$ of R\&D investment by participating firm in 1998; this already low figur dropped further to a dismal $0.65 \%$ by $2000 .{ }^{4}$ The importance of non-monetary benefit is also reflecte by the fact that certain firm applied to participate in Profarma without asking for research funding.

Apart from rewarding and encouraging $R \& D$, the public administration also desired to include as many firm as possible, because the program provided it with detailed information about the state of the pharmaceutical industry. In that sense Profarma can be called a success: in its last year the program included 56 firms which made up $85 \%$ of the market in terms of sales. ${ }^{5}$

\section{Empirical analysis of Profarma (1998-2000)}

Our empirical analysis has three objectives. First, using data on all companies that participated in Profarma, we contrast the ex ante announced criteria with their ex post implementation by the Spanish Ministry of Science and Technology. Second, we analyze whether the criteria that matter in the implementation of Profarma correspond to those criteria that the empirical literature has found to have the most important effect on innovation. Third, we want to uncover any hidden criteria that might have been used. In particular, we consider whether any discrimination was made based on the geographical origin of firms

\subsection{Data and evaluation procedure}

As shown in Fig. 1, the procedure to rank firm is based on both scientifi and economic criteria. The scientifi evaluation is responsibility of the Scientific

\footnotetext{
${ }^{4}$ It should be mentioned, however, that in the year 2000 the Ministry of Science and Technology started providing zero interest loans, in addition to direct financia support. Unfortunately, we do not have data on their magnitude.

5 Total sales of participating firm amounted to 7716 million $€$, whereas total sales of the sector were 9049 million $€$ (according to data of the Instituto Nacional de Estadistica).
}

Assessment Committee. The committee's members are government official from the Ministry of Science and Technology and the Ministry of Health. With the help of outside consultants they assign a scientifi grade to each company after evaluating their scientifi capacity. Economic evaluation is the responsibility of the Ministry of Science and Technology. It is based on a number of quantifiabl criteria that firm provide on their application forms. The final grade is a combination of the scientific grade and the economic evaluation. How the scientifi and the economic criteria were translated into the fina grade, and whether other more subjective aspects entered into play, is not clearly spelled out.

The call for applications specifie the evaluation criteria. These are the ones we use in our empirical analysis. The data were collected manually, using the application forms of all firm as our primary data source. The Ministry of Science and Technology also provided us with the scientifi grades. Our data set therefore covers the entire population of participating firms In 1998, the Ministry of Science and Technology received 51 applications; in 1999 that number remained stable at 50 ; and in 2000 there was a slight increase to 56 applications. Taking into account missing values for some companies, we were eventually left with around 150 observations. Note that most of the firm show up in all 3 years; the total number of different firm over the 3 years is 59 .

We now give a list of all the variables we will use in the empirical analysis. This information is summarized in Fig. 2.

1. The scientific grade classifie companies into fi e different groups. Since this classificatio presents a mere ordering, we do not assign number grades to the different groups. Instead, we rely on dummy variables to tell us the numerical distance between grades. (The names of the dummies used in the subsequent econometric analysis are given in brackets.)

a. Companies in Group A (companies with research activity and production plants in Spain) and Group C (with research activity and no production plants) are classifie into the following categories:

- Excellent (SCIENTIFIC DUMMY GRADE 5),

- Very good (SCIENTIFIC DUMMY GRADE 4), 


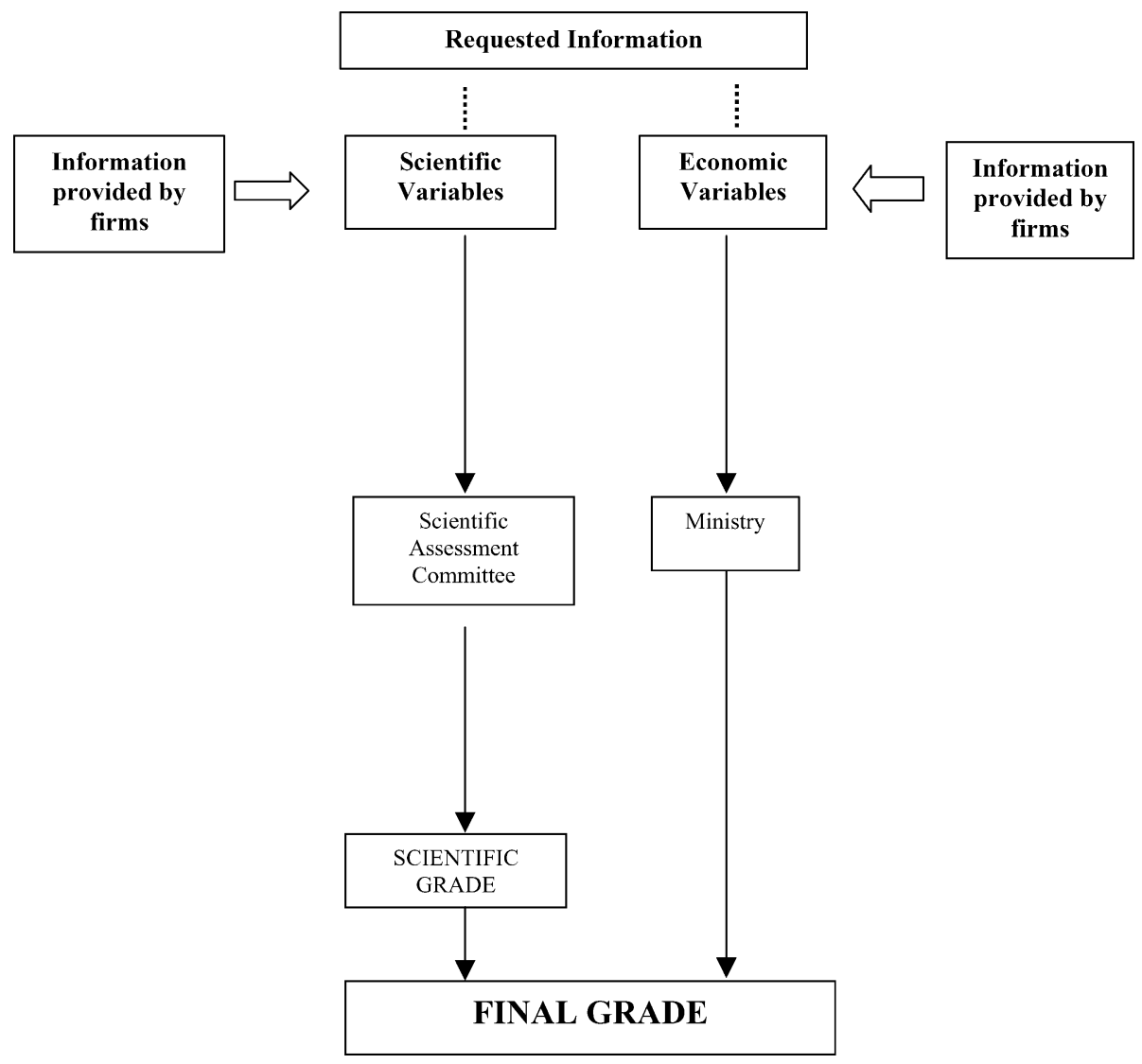

Fig. 1. Evaluation procedure and determinants of the fina grade.

- Good (SCIENTIFIC DUMMY GRADE 3),

- Acceptable (SCIENTIFIC DUMMY GRADE 2).

b. The companies in Group B have development activities and production plants, but do no research (SCIENTIFIC DUMMY GRADE 1). ${ }^{6}$

2. For the economic criteria, we use all available information from the application forms. These correspond to the indicators announced in the call for applications by the Ministry of Science and Technology. (Again, the names of variables appear in brackets.)

- The existence of an R\&D center in the company ( $R \& D$ CENTER $=1$ if center exists; 0 otherwise).

\footnotetext{
6 To be precise, firm in Group B are divided into "Positive" and "Negative" ones. However, none of the firm were classifie as "Negative".
}

- R\&D spending as a fraction of sales (R\&D/SALES).

- Outside cooperation (COOPERATION = 1 if company cooperates with outside firm or institutions; COOPERATION $=0$ if it does not).

- Patent expenses, in millions of $€$ (PATENT SPENDING).

- R\&D investment, in millions of $€(R \& D$ INVESTMENT).

- Total investment, in millions of $€$ (TOTAL INVESTMENT).

- Sales of pharmaceuticals, in millions of $€$ (SALES PHARMACEUTICALS).

- Sales of raw materials, in millions of $€$ (SALES RAW MATERIALS).

- Trade balance, in millions of $€$ (TRADE BALANCE). 


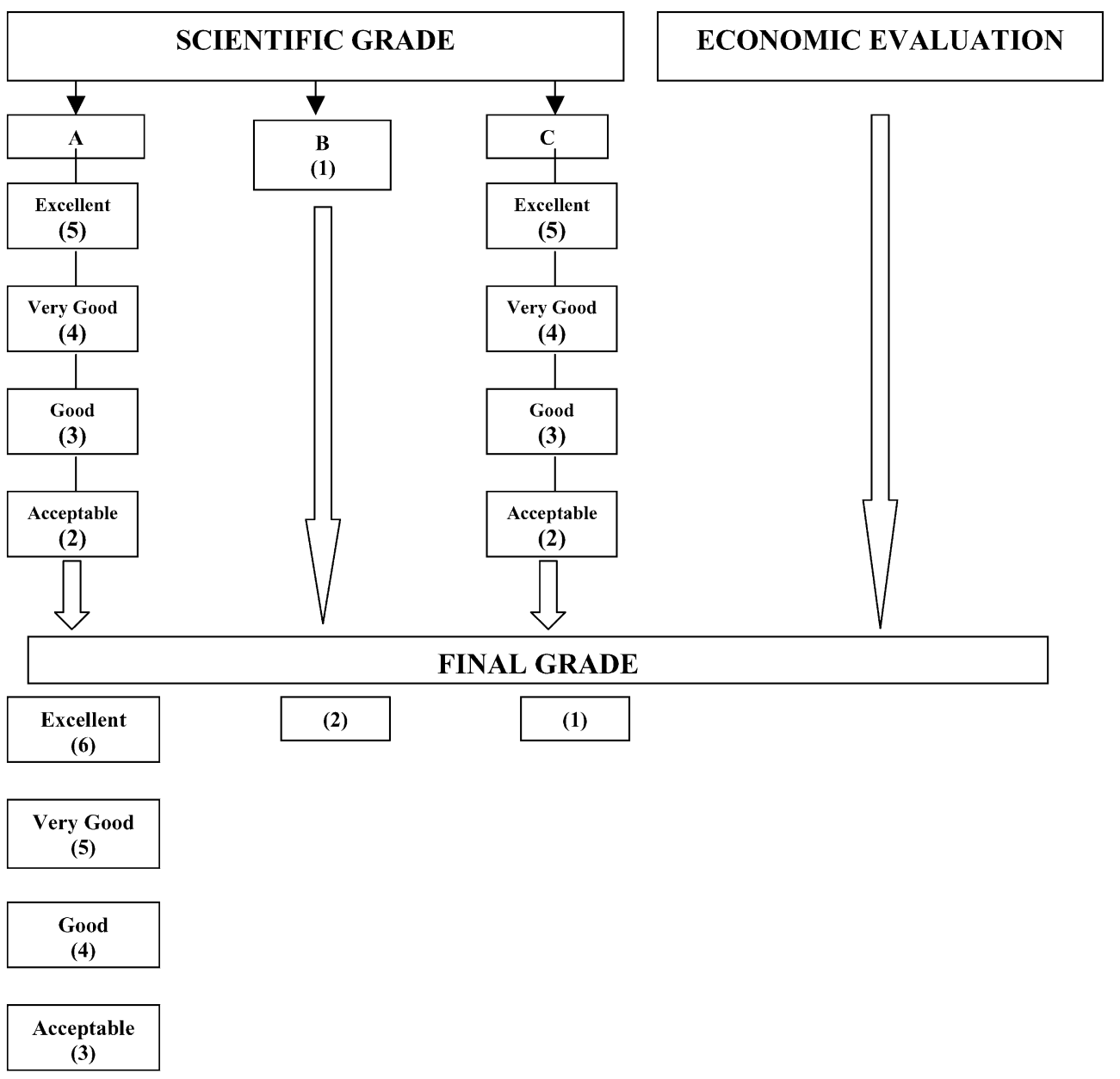
A: Firms with R\&D and production plants in Spain
B: Firms with development activities and production plants in Spain
C: Firms with R\&D. No plant

Fig. 2. Firms' typology.

- Net profits in millions of $€$ (NET ACCOUNTING PROFIT).

3. The scientific grade and the economic criteria give rise to a final grade. The fina grade orders companies into different categories. To facilitate our analysis, we assign corresponding number grades to these different groups. Since the fi nal grades should not be viewed as a cardinal ranking, we will use an ordered probit as our estimation technique. a. Group A: Companies with research activity and production plants.

- Excellent (grade 6),

- Very good (grade 5),

- Good (grade 4),

- Acceptable (grade 3).

b. Group B: Companies with development activities and production plants (grade 2).

c. Group C: Companies with research activity and no production plants (grade 1). 
In the subsequent econometric analysis the fina grade will be the dependent variable, with the economic criteria and the scientifi grade as the regressors.

\subsection{Ex ante criteria versus ex post implementation}

Although the officia call for applications by the Ministry of Science and Technology specifie the evaluation criteria, it did not reveal the relative importance of each one of them. To see how the ex post implementation may have differed from the ex ante announcement, we look at what the data tells us about the actual evaluation process.

We regress the fina grade on the economic criteria and the scientifi dummy grades. Since the fina grade reflect an ordinal - rather than a cardinal - ranking, we use an ordered probit as our estimation technique. Indeed, our ranking says that a fina grade of 6 is better than a fina grade of 5 , and that a fina grade of 5 is better than a fina grade of 4 , without implying that the difference between 6 and 5 is the same as the difference between 5 and 4 . The basic observation is a firm-yea . Since many of the firm apply in all 3 years of the Profarma program, we specify that observations are independent across firms but not necessarily within firms As already mentioned, in our empirical analysis we use all quantifiabl criteria announced in the call for applications. In that sense, we take our theoretical model as exogenously given.

The results are reported in Table 1. Column (1) regresses the fina grade on all economic criteria and on the scientifi dummy grades. The number in brackets give the $P$-values. To facilitate reading, the coefficient in bold are statistically significan at the 5\% level. Apart from the scientifi grades, four variables fall into that category: patent spending, $R \& D$ investment, the sales of pharmaceuticals and the trade balance. The coeffi cients on all of these four variables are positive, implying that an increase in any one of them has a positive effect on the fina grade. As can be seen in column (1), the effect of the scientifi dummy grade is measured relative to "scientifi dummy grade 3", which has been dropped from the regression. Not surprisingly, grades higher than 3 have a positive effect on the fina grade, whereas grades lower than 3 have a negative effect.

With a data set of 150 observations, using four dummy variables for the different scientifi grades is potentially costly in terms of loss of degrees of free- dom. To remedy this issue, we reduce the different dummies to just one variable. Our results in column (1) suggest that the difference in coefficient between any two adjacent scientifi dummy grades is not significantly different from 1 . It therefore seems acceptable to interpret the ordinal ranking of the fi e scientifi dummy grades as a cardinal ranking. As can be seen in column (2), this approximation is reasonable. The variables which are statistically significan at the $5 \%$ level are the same as those in column (1). The values of their coefficient change very little. More importantly, the estimation is more precise, as reflecte by their lower $P$-values.

Although we use the call for applications as a guide for deciding which variables to include as regressors, there may be good theoretical reasons to think that certain variables are strongly related. For instance, our basic regression includes $R \& D$ spending as a fraction of sales, $R \& D$ investment and sales of pharmaceuticals. It may be advisable to leave out one of these three regressors, for instance, $R \& D$ spending as a fraction of sales. This is done in column (3). As can be seen, the results do not change significantl. Furthermore, we would also expect total investment, net accounting profit and sales of pharmaceuticals to be related. This is confirme by the correlogram in Table 2 . In column (4) we therefore take out net accounting profits and in column (5) we also drop total investment. Again, there is no appreciable effect on the results.

Another question of interest is whether the evaluation process changed over the 3 years of the plan. To explore this possibility, we introduce time dummies for 1999 and for 2000 in column (6). Neither show up to be significant We also investigated whether the coefficient of the different independent variables changed from year to year. This is not the case, so we refrain from reporting the results here.

Some of the criteria, such as having an R\&D center or collaborating with outside firm (or institutions) may show up to be insignifican because the scientifi grade picks up their effect. To see whether this is the case, column (7) drops the scientifi grade from the regression. As can be seen, this does not change the variables which are statistically significan at the 5\% level.

All these robustness checks leave us with the exogenously given model (column (2)) as our preferred specification We now turn to the quantitative 
Table 1

Determinants of the fina grade (ordered probit)

\begin{tabular}{|c|c|c|c|c|c|c|c|}
\hline Dependent variable: fina grade & (1) & (2) & (3) & (4) & $(5)$ & $(6)$ & (7) \\
\hline R\&D center & $-0.010(0.983)$ & $0.074(0.890)$ & $0.192(0.734)$ & $0.183(0.739)$ & $0.130(0.807)$ & $0.054(0.925)$ & $0.169(0.738)$ \\
\hline $\mathrm{R} \& \mathrm{D} / \mathrm{sales}$ & $-4.951(0.222)$ & $-3.772(0.368)$ & & & & $-3.805(0.366)$ & $-0.584(0.902)$ \\
\hline Cooperation & $-0.668(0.247)$ & $-0.606(0.272)$ & $-0.475(0.337)$ & $-0.475(0.337)$ & $-0.465(0.329)$ & $-0.606(0.278)$ & $-0.828(0.121)$ \\
\hline Patent spending & $\mathbf{3 . 1 8 9}(0.011)$ & $\mathbf{3 . 2 5 6}(0.011)$ & $\mathbf{3 . 0 8 9}(0.016)$ & $\mathbf{3 . 0 8 8}(0.016)$ & $\mathbf{3 . 1 2 7}(0.015)$ & $\mathbf{3 . 3 0 7}(0.012)$ & $5.111(0.001)$ \\
\hline $\mathrm{R} \& \mathrm{D}$ investment & $\mathbf{0 . 4 2 4}(0.033)$ & $\mathbf{0 . 4 5 4}(0.009)$ & $\mathbf{0 . 3 9 7}(0.014)$ & $0.399(0.016)$ & $\mathbf{0 . 3 5 0}(0.038)$ & $\mathbf{0 . 4 6 4}(0.011)$ & $\mathbf{0 . 6 6 5}(0.018)$ \\
\hline Total investment & $-0.026(0.334)$ & $-0.032(0.321)$ & $-0.027(0.395)$ & $-0.027(0.393)$ & & $-0.031(0.353)$ & $-0.023(0.439)$ \\
\hline Sales pharmaceuticals & $\mathbf{0 . 0 0 5}(0.022)$ & $\mathbf{0 . 0 0 5}(0.025)$ & $\mathbf{0 . 0 0 6}(0.005)$ & $\mathbf{0 . 0 0 6}(0.012)$ & $\mathbf{0 . 0 0 5}(0.032)$ & $\mathbf{0 . 0 0 5}(0.026)$ & $\mathbf{0 . 0 0 7}(0.003)$ \\
\hline Sales raw materials & $0.007(0.230)$ & $0.008(0.229)$ & $0.008(0.243)$ & $0.008(0.237)$ & $0.007(0.269)$ & $0.008(0.235)$ & $0.007(0.477)$ \\
\hline Trade balance & $\mathbf{0 . 0 1 1}(0.004)$ & $\mathbf{0 . 0 1 0}(0.014)$ & $\mathbf{0 . 0 0 9}(0.022)$ & $\mathbf{0 . 0 0 9}(0.024)$ & $\mathbf{0 . 0 0 8}(0.040)$ & $\mathbf{0 . 0 0 9}(0.013)$ & $0.008(0.029)$ \\
\hline Net accounting profi & $-0.002(0.885)$ & $-0.001(0.939)$ & $-0.002(0.887)$ & & & $-0.001(0.974)$ & $0.003(0.823)$ \\
\hline Scientifi grade & & $0.745(0.035)$ & $\mathbf{0 . 7 1 7}(0.042)$ & $\mathbf{0 . 7 1 6}(0.041)$ & $\mathbf{0 . 7 1 3}(0.037)$ & $\mathbf{0 . 7 4 1}(0.039)$ & \\
\hline Scientifi grade 1 & $-1.204(0.030)$ & & & & & & \\
\hline Scientifi grade 2 & $-\mathbf{0 . 2 8 1}(0.465)$ & & & & & & \\
\hline Scientifi grade 4 & $1.170(0.036)$ & & & & & & \\
\hline Scientifi grade 5 & $2.191(0.171)$ & & & & & & \\
\hline Year 2000 & & & & & & $-0.071(0.681)$ & \\
\hline Year 1999 & & & & & & $-0.028(0.807)$ & \\
\hline Pseudo $\mathrm{R}^{2}$ & 0.2939 & 0.2841 & 0.2799 & 0.2799 & 0.2774 & 0.2842 & 0.18999 \\
\hline
\end{tabular}

$P$-values given in parentheses. Coefficient in bold are statistically significan at the $5 \%$ level. 
interpretation of the results. Given that we are using an ordered probit, the coefficient in Table 1 do not have a direct interpretation. For instance, the coefficien of 0.745 on the scientifi grade does not mean that an increase in the scientifi grade by 1 point leads to an increase in the fina grade of 0.745 . This is because we are interpreting the fina grade as a mere ordinal ranking, so that an increase in the fina grade of 0.75 does not have a precise meaning. Instead, with an ordered probit the relevant question to ask is how the probability of getting one grade, rather than another, changes in function of the explanatory variables. Table 3 gives us this information. Consider, for instance, the scientifi grade variable. An increase in the scientifi grade by 1 point decreases the probability of getting a fina grade of 1, 2 and 3 by, respectively, $0.13,0.13$ and 0.04 ; and increases the probability of getting a fina grade of 4,5 and 6 by, respectively, $0.05,0.09$ and 0.16 .

To interpret the other four variables which are statistically significan (patent spending, R\&D investment, sales of pharmaceuticals and the trade balance) we look at how the probability of getting a high grade (above 3 ) changes when we increase each of these variables by one standard deviation. For patent spending this raises the probability of getting a high grade by 0.13 ; for R\&D investment the probability goes up by 0.14 ; for sales of pharmaceuticals we get a figur of 0.21 ; and for the trade balance we fin 0.18 .

A firs conclusion from this section is that certain criteria which were ex ante announced to be important turned out not to matter ex post: this is the case of, for instance, having an R\&D center and cooperating with other firm and institutions. This remains true under a variety of specifications It may therefore be misleading to judge the effectiveness of an R\&D program based exclusively on its design. How well or how badly an R\&D program performs has to do with its implementation, and not its design. This distinction is not innocuous because, as we show for the case of Profarma, the implementation may indeed differ significantl from its design.

A second conclusion is that, in spite of the discrepancy between ex ante and ex post criteria, the program's overall implementation is in line with its objectives. Our results indicate that R\&D investment and patent spending are important in determining the ranking of firms This is consistent with a series of papers on the market value of innovation, arguing that $R \& D$ invest-

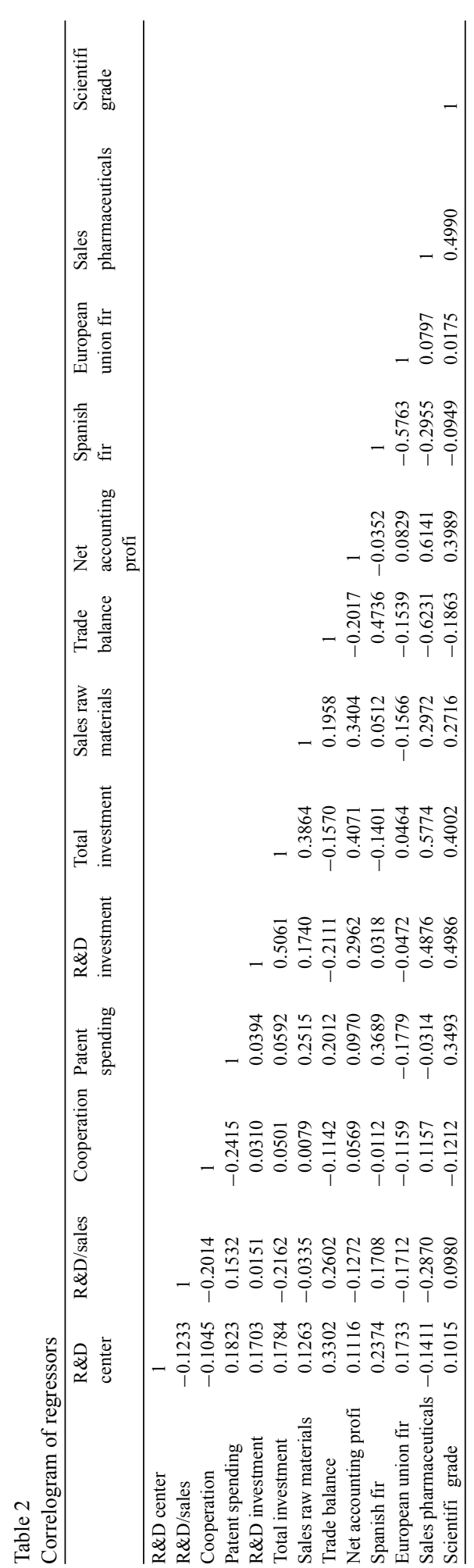


Table 3

Effect of evaluation criteria on the probability of getting different fina grades

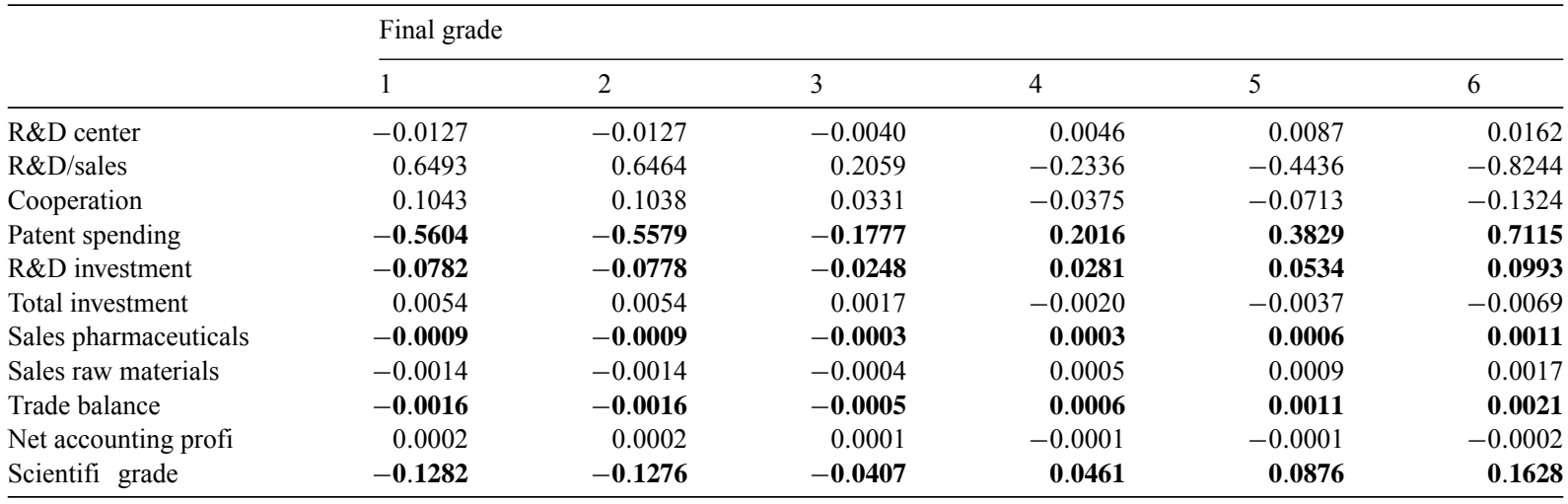

These results are based on the regression in column 2 of Table 1 . The numbers in bold correspond to criteria which are statistically significan at the $5 \%$ level. To interpret this table, consider, for example, the last line. An increase in the scientifi grade by 1 point decreases the probability of getting a fina grade of 1 by 0.1282 , and it increases the probability of getting a fina grade of 6 by 0.1628 .

ment and patent counts are good indicators of innovative activity (Pakes, 1985; Griliches et al., 1987; Hall, 2000). Interestingly, the pharmaceutical sector is the only one for which patents add to the market value of firm above and beyond R\&D investment (Griliches et al., 1991). The fact that R\&D investment and patent spending are two out of the fi e statistically signifi cant criteria indicates that the choice of the Spanish authorities is consistent with what is already known from the empirical literature. It also shows that they are not only worried about R\&D inputs (such as R\&D spending) but also about R\&D outputs (such as patent spending). We now briefl discuss the other three statistically significan criteria: the scientifi grade, the sales of pharmaceuticals, and the trade balance. Clearly, the scientifi grade is closely related to $\mathrm{R} \& \mathrm{D}$. Using the sales of pharmaceuticals to determine the ranking of firm may also make sense if we believe it is a measure of translating R\&D into commercial success. The trade balance, in contrast, seems to have more to do with industrial policy than with encouraging $R \& D$.

\subsection{Uncovering the premium to Spanish and European Union firms}

In this section we investigate whether Spanish (or European Union) companies received favorable treatment. Over the three years considered, Spanish firm obtained an average fina grade of 3.75 on a scale from 1 to 6 , compared to 3.65 for European
Union firm and 3.15 for firm from the rest of the world.

These higher grades could of course simply reflec better R\&D performance by Spanish firms At firs sight, the data lend support to this explanation. Fig. 3 shows $R \& D$ expenditure as a ratio of sales of ethical drugs (distinguishing between firm from Spain, the European Union, and the rest of the world). As can be seen, Spanish firm performed clearly better than the rest. However, not all R\&D indicators point in the same direction. For instance, the average scientifi grade for Spanish firm stood at 2.7, lower than the 3.1 for nonEuropean Union firms

Regardless of what these indicators tell us, our goal is to check whether there is any residual preferential treatment after controlling for all the economic criteria and the scientifi grade. We therefore regress the fina grade on the same list of indicators as before, with the only difference that we now include two dummy variables to control for the origin of firms The dummy SPANISH FIRM takes on value 1 if more than $50 \%$ of the firm s capital is Spanish and 0 if not; similarly, the variable EUROPEAN UNION FIRM takes on value 1 if more than $50 \%$ of its capital is from the European Union and value 0 otherwise.

Table 4 reports the results for our ordered probit estimation. Column (1) suggests that Spanish and European Union firm received preferential treatment: after controlling for all economic criteria and the scientifi grade, the coefficient on the Spanish fir and 


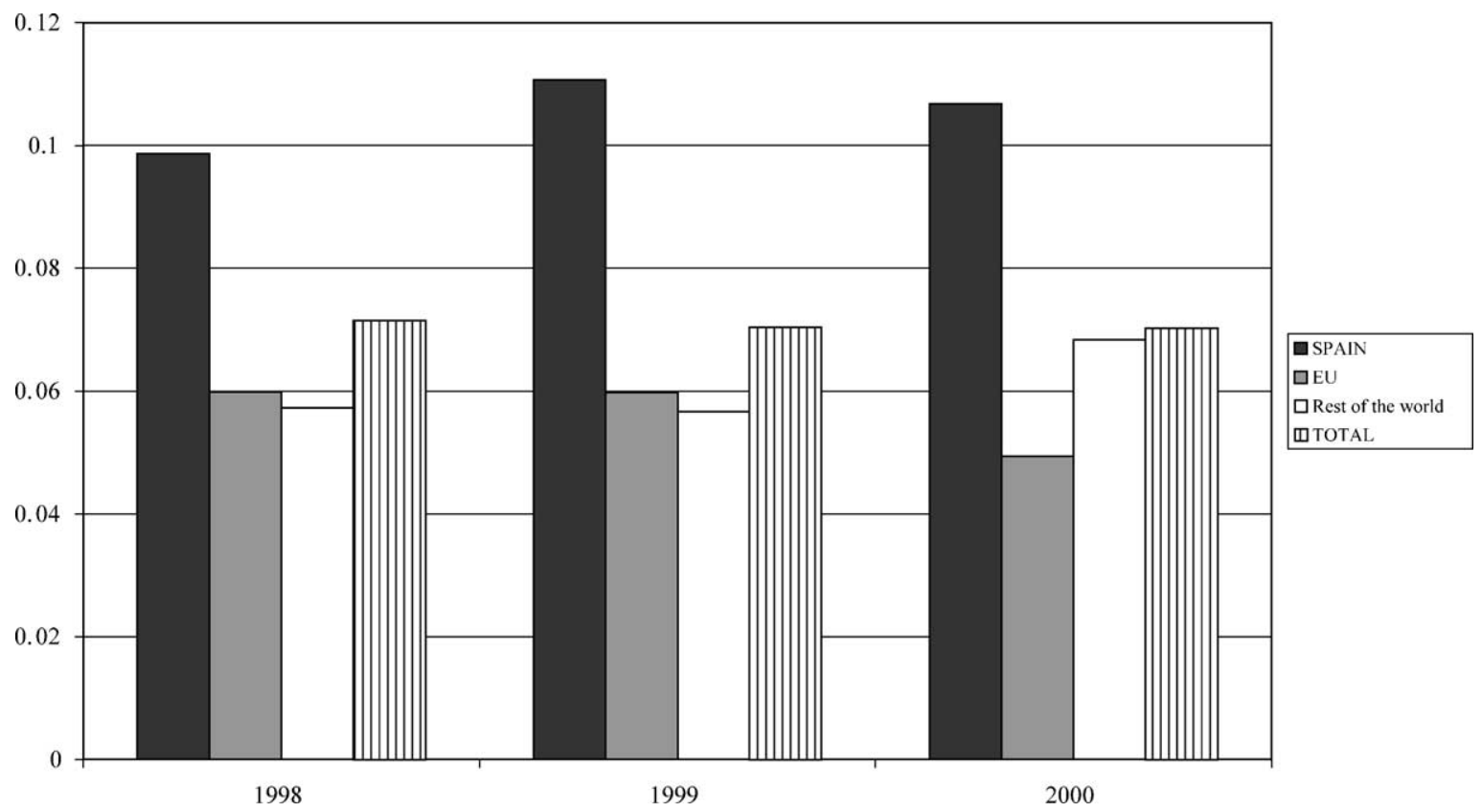

Fig. 3. R\&D expenditure/sales of ethical drugs.

the European Union fir dummies are positive and statistically significant As for the other explanatory variables, there are two changes compared to our previous results. First, patent spending ceases to be significant Second, the trade balance becomes insignificant in favor of the sales of raw materials. Note that this latter change does not affect our previous conclusions, since trade balance and the sales of raw materials reflec the same concern of the public administration, i.e. the reduction of imports (and possibly domestic job creation). Indeed, firm that produce their own raw materials (and sell them) tend to be verti-

Table 4

Determinants of the fina grade (ordered probit), controlling for fir origin

\begin{tabular}{lrrr}
\hline Dependent variable: fina grade & $(1)$ & $(2)$ & $(3)$ \\
\hline R\&D center & $-0.426(0.18)$ & $-0.134(0.66)$ & $0.108(0.86)$ \\
R\&D/sales & $-3.893(0.17)$ & $-0.158(0.95)$ & $9.686(0.23)$ \\
Cooperation & $-0.511(0.30)$ & $-0.692(0.15)$ & $1.135(0.17)$ \\
Patent spending & $1.624(0.26)$ & $\mathbf{4 . 8 0 4}(0.00)$ & $\mathbf{0 . 7 4 8}(0.00)$ \\
R\&D investment & $\mathbf{0 . 4 5 9}(0.04)$ & $-0.017(0.49)$ & $0.365(0.30)$ \\
Total investment & $-0.017(0.49)$ & $\mathbf{0 . 0 0 7}(0.00)$ & $-0.050(0.27)$ \\
Sales pharmaceuticals & $\mathbf{0 . 0 0 5}(0.02)$ & $\mathbf{0 . 0 1 2}(0.05)$ & $0.004(0.29)$ \\
Sales raw materials & $\mathbf{0 . 0 1 8}(0.01)$ & $\mathbf{0 . 0 0 6}(0.05)$ & $\mathbf{0 . 0 2 4}(0.05)$ \\
Trade balance & $0.006(0.10)$ & $-0.002(0.88)$ & $0.006(0.36)$ \\
Net accounting profi & $-0.011(0.36)$ & & $0.012(0.58)$ \\
Scientifi grade & $\mathbf{0 . 9 3 1}(0.00)$ & $\mathbf{0 . 6 7 2}(0.02)$ & $\mathbf{3 . 6 4 4}(0.00)$ \\
Spanish fir & $\mathbf{1 . 5 3 3}(0.00)$ & $\mathbf{0 . 7 6 4}(0.01)$ & $-0.417(0.51)$ \\
European union fir & $\mathbf{1 . 1 3 2}(0.00)$ & 0.21 & $-0.748(0.19)$ \\
Pseudo R & 0.33 & 149 & 0.83 \\
Number of observations & 149 & & 134 \\
\hline
\end{tabular}

$P$-values given in brackets. Coefficient in bold are statistically significan at the $5 \%$ level. 
cally integrated, and need not rely on imports for their production.

As before, certain variables could be statistically insignificant because their effect is picked up by the scientifi grade. In column (2) we therefore leave out the scientifi grade, and fin that patent spending and the trade balance now show up to be significant Moreover, the preferential treatment of Spanish and European Union firm is bigger when we include the scientifi grade than when we do not. In addition, the relative advantage of being from Spain rather than from the European Union is also greater. This reflect a simple fact: Spanish firm received a scientifi grade of 3.7 on average, compared to 3.9 for European Union firms and 4.1 for firm from the rest of the world.

To interpret the payoff for being from Spain or the European Union, we focus on column (1), and calculate what the coefficient imply about the probabilities of getting a high fina grade. The results are reported in Table 5. Being Spanish increases the probability of getting a high fina grade (above 3 on a scale from 1 to 6) by 0.61 . In the case of European Union firms the effect is 0.45 . To put these magnitudes into perspective, the effect of being Spanish is equivalent to an increase in the scientifi grade by 1.65 points (on a scale from 1 to 5 ). It is also equivalent to increasing pharmaceutical sales by 3 standard deviations, and raising $R \& D$ investment by more than 4 standard deviations.
One could of course argue that it makes sense for the Spanish authorities to encourage research in Spain, rather than abroad. But this is not the point: data on all firm in our sample refer to operations in Spain. In other words, our information on multinationals is limited to their activities in Spain. The apparent discrimination is based on whether the firm s capital is Spanish, not on whether its operations occur in Spain.

This leaves us with the question: what is the underlying reason for the premium received by Spanish and European Union firms One possible explanation is that R\&D by Spanish firm is more likely going to lead to production in Spain. To test this hypothesis, in column (3) we re-run our standard regression on the subgroup of firm that have production plants in Spain. This amounts to leaving out 15 observations. When doing so, the preferential treatment disappears. Though striking, this result is not entirely surprising. As mentioned before, when the Ministry of Science and Technology assigns the fina grade, firm with R\&D activities but no production plants get relegated to Group $\mathrm{C}$, corresponding to the lowest grade.

This implies that firm get heavily penalized for not having production plants. Since these firm are by and large from outside the European Union, this shows up as favorable treatment to local firms This explains some of our previous findings Whereas Spanish firm get on average a low scientifi grade of 3.7, compared

Table 5

Effect of evaluation criteria on the probability of getting different fina grades, controlling for fir origin

\begin{tabular}{|c|c|c|c|c|c|c|}
\hline & \multicolumn{6}{|c|}{ Final grade } \\
\hline & 1 & 2 & 3 & 4 & 5 & 6 \\
\hline $\mathrm{R} \& \mathrm{D}$ center & 0.0734 & 0.0731 & 0.0233 & -0.0264 & -0.0501 & -0.0932 \\
\hline $\mathrm{R} \& \mathrm{D} / \mathrm{sales}$ & 0.6701 & 0.6671 & 0.2125 & -0.2411 & -0.4578 & -0.8508 \\
\hline Cooperation & 0.0879 & 0.0875 & 0.0279 & -0.0316 & -0.0601 & -0.1116 \\
\hline Patent spending & -0.2796 & -0.2783 & -0.0886 & 0.1006 & 0.1910 & 0.3550 \\
\hline R\&D investment & -0.0789 & -0.0786 & $-\mathbf{0 . 0 2 5 0}$ & 0.0284 & 0.0539 & 0.1002 \\
\hline Total investment & 0.0030 & 0.0030 & 0.0010 & -0.0011 & -0.0021 & -0.0038 \\
\hline Sales pharmaceuticals & -0.0009 & -0.0009 & -0.0003 & 0.0003 & 0.0006 & 0.0011 \\
\hline Sales raw materials & -0.0031 & -0.0031 & -0.0010 & 0.0011 & 0.0021 & 0.0040 \\
\hline Trade balance & -0.0010 & -0.0010 & -0.0003 & 0.0003 & 0.0007 & 0.0012 \\
\hline Net accounting profi & 0.0019 & 0.0019 & 0.0006 & -0.0007 & -0.0013 & -0.0024 \\
\hline Scientifi grade & -0.1602 & -0.1595 & -0.0508 & 0.0576 & 0.1095 & 0.2034 \\
\hline Spanish fir & -0.2640 & -0.2628 & $-\mathbf{0 . 0 8 3 7}$ & 0.0950 & 0.1803 & 0.3351 \\
\hline European union fir & -0.1949 & -0.1940 & -0.0618 & 0.0701 & 0.1332 & 0.2475 \\
\hline
\end{tabular}

These results are based on the regression in column 1 of Table 4 . The numbers in bold correspond to criteria which are statistically significan at the $5 \%$ level. To interpret this table, consider, for example, the second to last line. Being Spanish decreases the probability of getting a fina grade of 1 by 0.2640 , while it increases the probability of getting a fina grade of 6 by 0.3351 . 
to a higher 4.1 for non-European firms they end up with a high fina grade of 3.75 , compared to a lower 3.15 for non-European firms Such a policy of supporting local production is not uncommon. For instance, Israel, a country in which public support to R\&D was markedly successful, makes subsidies conditional on future production in the country (Trajtenberg, 2002).

It is less clear how to interpret favoring local production. On the one hand, one could argue that part of the subsidies to R\&D should be counted as production or employment subsidies, and should therefore be analyzed as such (Trajtenberg, 2002). On the other hand, though, manufacturing may be an integral part of a firm s scientifi infrastructure in the case of the pharmaceutical industry (Pisano, 1997). ${ }^{7}$

\section{Concluding remarks}

This paper has studied how the Spanish Ministry of Science and Technology ranked pharmaceutical companies in the framework of Profarma, a government plan aimed at fostering R\&D. Our focus has been on the implementation, rather than the design of the plan. By using detailed firm-l vel data, we have shown remarkable differences between the ex ante and the ex post criteria. Uncovering differences between design and implementation, our paper suggests that too much attention may be given to analyze the optimality of the design, or to study the achievement of the objectives, and too little to its actual implementation. Even if selection criteria are optimal, the plan may fail if its implementation falls short.

In spite of this discrepancy between ex ante announced and ex post applied criteria, the plan's implementation has been shown to be broadly in line with its objectives. In particular, we found that R\&D investment and patent spending played a central role in evaluating firms From the empirical work by Griliches et al. (1991) we know that these two variables are good indicators for innovative capacity in the pharmaceutical industry.

Moreover, we have shown that the premium for being Spanish or European can be explained by the large penalty placed on firm that do not produce locally. This

\footnotetext{
${ }^{7}$ Pisano, op cit., pp. 229-230.
}

suggests that encouraging production and employment, and not just R\&D, may also one of the program's main priorities.

\section{Acknowledgement}

Raisa González built the database and helped with data processing. We thank the Subdirectorate General for Technological Programs of the Spanish Ministry of Science and Technology for providing us with data and continuous support; P. Albarrán, C.E. García, F. García Alonso, J. Jaumandreu, P. Marín, C. Lens, M. Shum, and three anonymous referees for helpful comments; and Fundación Salud, Innovación y Sociedad for financia support.

\section{References}

Arora, A., David, P.A., Gambardella, A., 1998. Reputation and competence in publicly funded science: estimating the effects on research group productivity. Annales d'Economie et Statistique 49/50, 163-198.

Buesa, M., Molero, J., 1998. Economía industrial de España. Civitas, Madrid.

David, P.A., Hall, B.H., Toole, A.A., 2000. Is public R\&D a complement or a substitute for private $R \& D$ ? A review of the econometric evidence. Research Policy 29, 497-529.

Gambardella, A., Orsenigo, L., Pammolli, F., 2000. Global competitiveness in pharmaceuticals. A European perspective. Report for the European Commission.

Griliches, Z., Hall, B.H., Pakes, A., 1991. R\&D, patents, and market value revisited: is there a second (technological opportunity) factor? Journal of Economics of Innovation and New Technology 1, 183-201.

Griliches, Z., Pakes, A., Hall, B.H., 1987. The value of patents as indicators of innovative activity. In: Dasgupta, P., Stoneman, P. (Eds.), Economic Policy and Technological Performance. Cambridge University Press, Cambridge, England, 97-124.

Hall, B., 2000. Innovation and market value. In: Barrell, R., Mason, G., O’Mahoney, M. (Eds.), Productivity, Innovation and Economic Performance. Cambridge University Press, Cambridge.

Hall, B., Van Reenen, J., 2000. How effective are fisca incentives for R\&D? A review of the evidence. Research Policy 29, 449-469.

Jacobzone, S., 2000. Pharmaceutical Policies in OECD Countries: Reconciling Social and Industrial Goals. OECD, Labour Market and Social Policy, Occasional Papers No. 40, Paris.

Jaffe, A.B., 2002. Building programme evaluation into the design of public research-support programmes. Oxford Review of Economic Policy 18, 22-34.

Klette, T.J., Møen, J., Griliches, Z., 2000. Do subsidies to commercial R\&D reduce market failures? Microeconometric evaluation studies. Research Policy 29, 471-495. 
Lach, S., 2002. Do R\&D subsidies stimulate or displace private R\&D? Evidence from Israel. Journal of Industrial Economics, L, 369-390.

Lerner, J., 1999. The government as venture capitalist: the long-run impact of the SBIR program. Journal of Business 72, 235-318.

Martin, C., 1999. La situación tecnológica. Cambio técnico y política tecnológica. In: García Delgado, J.L. (Ed.), España, Economía: ante el Siglo XXI. Espasa, Madrid.

Martin, S., Scott, J.T., 2000. The nature of innovation market failure and the design of public support for private innovation. Research Policy 29, 437-447.

Myro, R., et al., 2004. Dos décadas de crecimiento económico sostenido en España: un breve balance. In: Ontiveros, E., Lagares, M., García Delgado, J.L. (Eds.), Economistas 100. Veinte años de Economía española. Colegio de Economistas de Madrid, Madrid.
OECD, 2004. Science and Technology Statistical Compendium 2004. Meeting of the OECD Committee for Scientifi and Technological Policy at Ministerial Level, January 29-30, 2004, Paris.

Pakes, A., 1985. On patents, R\&D, and the stock market rate of return. Journal of Political Economy 93, 390-409.

Pisano, G.P., 1997. The Development Factory - Unlocking the Potential of Process Innovation. Harvard Business School Press, Boston, MA.

Scherer, F.M., 2000. The Pharmaceutical Industry. In: Culyer, A.J., Newhouse, J.P. (Eds.), Handbook of Health Economics. Elsevier, Amsterdam.

Sebastián, M., 2001. Spain in the EU: fiftee years may not be enough. Center for European Studies, Working PAPER \#96, Harvard University.

Trajtenberg, M., 2002. Government Support for Commercial R\&D: Lessons from the Israeli Experience. NBER, MIT Press. 